\title{
10
}

\section{MEETINGS MATTER \\ An exploratory case study on informal accountability and policy implementation in mainland China}

\author{
Bo Yan and Jiannan Wu
}

\section{Introduction}

Over the past three decades, mainland China's pursuit of 'top-down' strategies when directing local governments to introduce new policies has encountered significant 'wicked' problems that have inhibited improvements in government performance. To address these problems, the 18th Communist Party of China (CPC) Central Committee announced an unprecedented comprehensive reform to transform governmental functions and invigorate the market, and emphasised the importance of strengthening the implementation responsibilities of city-level governments.

The difficulties of implementing policy are in part due to deficiencies in mainland China's accountability system, leading some to call for the establishment and enforcement of formal accountability (e.g. through administrative punishment or sanctions) to encourage local cadres to achieve the central government's policy objectives. In particular, some proponents advocate the benefits and necessity of formal accountability tools, which may result in the stigmatising of local cadres, with the failure 
to implement policy ascribed to their misconduct. The adoption of these tools could deter irresponsible behaviour and make cadres comply with $\mathrm{CPC}$ policy implementation.

Formal accountability is not a panacea, however, and in practice is often accompanied by specific dilemmas. The approach usually refers to ex post facto processes in governance rather than ex ante inputs (Bovens 2007), so the accountability mechanism usually means punishment or sanctions for those held accountable for their conduct and performance (Behn 2001). Punishing the bad and rewarding the good in public sector cadres may appear reasonable, but it is difficult to foster unsolicited compliance or inspire proactive behaviour ex ante. Further, the accountability paradox suggests that strengthening accountability may hinder performance improvement or even encourage failure (Chan \& Gao 2009).

In fact, the formal accountability mechanism involves the CPC's centralised structure overlaying the state (the executive), the legislature and the judiciary, and operating through mainland China's five levels of decentralised government (Podger \& Yan 2013). There is no strong evidence that this can prevent idle policy implementation, such as implementing the essence of a previous meeting by convening the next meeting'. The prevailing sluggishness of policy implementation in mainland China suggests that some public sector leaders pursue substantive action slowly, cautiously waiting for each other to make further progress on specific policy implementation.

In practice, mainland China's governments do not solely rely on the formal accountability system to implement policy. China's complex accountability system differs from the Western system in that it consists of formal and informal mechanisms. Much of the reform agenda involves addressing wicked public problems characterised by complexity and uncertainty, and depends on cross-agency collaboration.

Government leaders find it difficult to use the formal accountability system to coordinate and constrain sectors administered by peer leaders. This unsettled situation requires the blurring of formal accountability lines and taking a holistic approach across organisational boundaries (Christensen \& Lægreid 2016). It also generates more space for informal accountability to affect informal behaviour, including networking through cross-agency meetings. 
Government leaders often work to solve wicked problems by establishing numerous small leading teams with many meetings at various levels. The question arises, therefore, do small leading-team meetings matter for policy implementation in mainland China? If so, why do they matter and what are the underlying social dynamics behind them? Little is currently known about how policy implementation is facilitated by cross-agency meetings, or how these shape informal accountability at mainland China's local government level.

To address this gap, this study explores how regular cross-agency meetings of a local government can contribute to policy implementation under pilot reform in mainland China, from the perspective of informal accountability. We use an exploratory case study to identify the key elements and ethnographic methods to collect data, which provide the empirical evidence for developing a theoretical framework. This case offers empirical evidence from mainland China, through which we can compare local government policy implementation with the experiences of other countries. The research must also extend from a macro-level analysis of accountability structure to a micro-level analysis of the subjective experiences of the actors involved in a specific accountability relationship (Yang \& Dubnick 2016). The findings will further the understanding of mainland China's administrative accountability system and its effects, and reveal the mechanism of mainland China's local policy implementation from a new perspective.

The article consists of four parts. First, we introduce the research background and clarify the research questions. The research design of the case study follows, along with a concise description of the case itself. We then take an ethnographic approach to analyse the effects of small leading-team meetings, and construct a preliminary framework to illustrate the informal accountability involved under the context of policy reform. Finally, the conclusion includes a summary of the academic contribution and presents implications for practitioners.

\section{Research design}

We use a single-case study strategy to investigate the effects of informal accountability associated with small leading-team meetings on the implementation of complex policy reforms at the local governmental level in mainland China. This strategy is particularly relevant when 'the number 
of variables of interest far outstrips the number of data points', and where the research questions mainly focus on 'how' and 'why'. The method is typically more explanatory than others, and can deal with operational links that must be traced over time (Yin 2003).

Despite the obvious weakness of any exploratory case study, it is still an effective method of bringing rich qualitative evidence to mainstream deductive research. The case need not be representative of a specific population (Eisenhardt \& Graebner 2007), although it should aim to illustrate a broader experience. It provides a snapshot, enabling us to illuminate meaningful characteristics of complex phenomena in a real-life setting without trying to control the context. For example, Yasuda (2015) used a case of failed food safety policy implementation to illustrate China's broad 'politics of scale', including central-local conflicts and trade-offs in its scale-management framework (Yasuda 2015).

For our selected case, J City's county-level government ( $\mathrm{J}$ Gov't) in eastern mainland China, we analysed the small leading-team meetings in which pilot reform was discussed. J City is a satellite of Q City, which is a provincial-level municipality in terms of its social and economic development planning, and thus has considerable fiscal autonomy, significantly higher official staffing authority than other municipalities, and strong fiscal conditions. Mainland China's county system has existed for two millennia and its boundaries have remained largely intact and, as the saying goes, 'good governance of the whole country depends on the counties being well governed'. Of the four levels of sub-national government, county-level governments are endowed with wide-ranging responsibilities, including comprehensive functions for implementing higher level government policies and for initiating and administering their own policies (Wu et al. 2017).

Following the guidance of the Q City government, J Gov't launched a comprehensive pilot reform program in August 2013 that covered economic, administrative and social affairs. As academic experts invited to help J Gov't implement the reform proposal, we regularly conducted field investigations and collected data for the period April 2013 to January 2014. Ethnographic methods, including participatory observations, in-depth interviews and document reviews, were also used to elicit findings on the realities of J Gov't's practice. We also used textual and social network analysis to explore the complex set of relationships and to achieve a degree of data triangulation. 


\section{Case description}

\section{Context}

The pilot reforms of the J Gov't are commonly regarded as reflecting a particularly active response to the national innovation-driven development strategy of the central government. According to the State Premier Keqiang Li, 'Deeper reform is the way forward', which reveals the ambition and willingness of mainland China's government to promote structural reform and to expedite the transition to a sustainable growth model, increasingly driven by innovation and consumption rather than state-led investment. A combination of policy tools is expected to be assembled to help drive regional development, and to strike a better balance between the state and the market by offering a more enabling business environment and a leaner but effective government.

A key challenge to this ambition is how local government can make progress on this grand reform strategy. The model of 'planning and experimentation under hierarchy' (Heilmann \& Melton 2013) suggests that it is common practice for higher level government in mainland China to provide local governments with both policy safeguards and policy discretion to 'go ahead of the rest and try new things out'. J Gov't was urged to launch comprehensive reform in the name of transforming government functions, mainly by focusing on streamlining administration and delegating power, strengthening regulation and ensuring better provision of public goods and services.

The reform covers 10 policy domains, 41 policy categories and 74 policy tasks in total, ${ }^{1}$ so all of the township-level governments and almost all of the principal bureaus in J Gov't were involved in this policy experiment. The leadership team consists of the mayor, one first deputy mayor (FDM), and five deputy mayors (DMs). The FDM and DMs are peers and each has different duties in assisting the mayor in directing and steering subordinates. They are each in charge of managing a number

1 The 10 policy domains are: removing administrative approval, removing administrative charge, removing certification, centralising administrative approval, centralising law enforcement, centralising trading, centralising payment, streamlining business registration, normalising management of NGOs, and trade and investment facilitation. Corresponding policy tools reconcile the demands from National Structural Reform on 'Streamlining administration and delegating power, strengthening regulation, facilitating public goods provision'. 
of the principal bureaus, and coordinating the vertical administrative institutions (VAIs). A VAI is a type of bureau directly managed by and accountable to the respective central or provincial government bureaus rather than city-level government.

For example, J Gov't has no power to appoint or remove the leadership of the Bureau of Quality and Technology Supervision (BQTS) as it is a provincial VAI, whereas most of the other bureaus (e.g. the Administrative Service Center (ASC) and the Bureau of Human Resources and Social Security) are jurisdictional administrative institutions and their personnel and fiscal or other vital resources are dependent on J Gov't. Thus, the complex formal accountability structure makes it difficult for the FDM or DMs to coordinate each other's subordinate sectors (whether or not they are VAI) as they each have different 'turf' to maintain.

The local cadres, however, recognised the considerable complexity, uncertainty and risk associated with the reform and informally expressed unwillingness and a lack of ability to promote the reform locally. The leaders of J Gov't were squeezed from above and below in that they not only had to conduct the pilot reform in response to the direction from Q City, but also had to address the serious concerns and lobbying of their subordinates. They feared that, at the beginning of the process, 'the more active the reform is, the more passive the individual is'. Many of the bureau leaders are middle-level cadres responsible for implementing aspects of the reform and reporting progress to the J Gov't, and they were concerned that their leaders were ignoring their bureaus' tight budgets and heavy ongoing duties, along with other obstacles to implementation.

Even frontline workers who were grassroots cadres in bureaus and township-level governments were fearful that the reform was too burdensome for them, and some complained that 'we are incapable of getting things done in this timeframe'. They also believed that they would be trapped if they made and implemented new policies faster than superior agencies ('The more aggressive the junior staff member is, the more embarrassing it will be if their changes are not first endorsed by the higher-up' ---下动上不动越动越被动). Thus, many local cadres were reluctant to implement the reform at the beginning and responded slowly to the directive. 


\section{Conduct of reform}

To promote and manage the implementation of the pilot policy reform, J Gov't established a small leading team and set up a series of regular meetings. The team's regular weekly or bi-weekly meetings were led by the FDM, with chief leaders from 13 selected bureaus constituting the core ongoing membership. Representatives of other relevant bureaus were invited to these meetings as necessary. In some cases, the CPC party secretary of J City, the mayor, the other DMs, and even deputy leaders of Q City in charge of corresponding projects, were also invited to attend. The FDM was always the de facto moderator of the meetings, delegated by the CPC's standing committee in J City to coordinate almost all bureaus involved in the pilot reform.

The meetings were organised to follow a series of steps for each explicit reform topic. First, the moderator revealed the problems and opportunities associated with policy implementation. Next, the bureau in charge of solving a specific problem was required to report on progress, provide relevant information and describe analytical investigations. The moderator facilitated subsequent dialogue among the meeting members who would then make or adjust decisions jointly, or agree to a means of conflict resolution for the topic addressed.

Meetings of this sort generate a policy-mandated network where an administrative superordinate actor can impose coordination and collaboration on other actors (Saz-Carranza et al. 2016). In this instance the FDM, as the meeting moderator, is the superordinate actor who sets the rules of the game, and has the unique authority to ask each actor to be responsible for their own performance. Moreover, they are obliged to follow up on previous decisions and commitments. Unlike meetings in private organisations, which usually serve as a venue for accomplishing work-related goals (Odermatt et al. 2017), this kind of meeting provides the means for displaying each actor's performance to others and involves image-building and other political behaviours. It requires a focus on the systematic progress of policy implementation, while also emphasising a shared approach to performance improvement through interaction within the network. 


\section{Consequences}

The meetings have resulted in an obvious structural change from hierarchical management to flattening and networking. J Gov't's previous formal hierarchical leadership structure has been transformed into a network associated with many mutual relationships. Although the small leading team is a temporary organisation and the network is ad hoc and additional to the formal structure, this change is meaningful. It engenders a blurring of lines of accountability, however, and some interactions in practice are different from the pre-reform formal line of accountability. For example, bureaus such as the ASC and BQTS have clearly become core actors within the policy-mandated network rather than of equal importance to other peripheral bureaus, as they were before the reform. They are now required to be directly accountable to the FDM regardless of their original domain or duties.

Consequently, almost all of the tasks required for policy implementation were completed by means of this network. The concerns of the local cadres before the reform were unfounded, and Q City government and higher level agencies admired the pilot reform of J Gov't. The party secretary of J Gov't was promoted to be one of the main leaders of the Q Gov't soon after the success of the J Gov't pilot reform. He is regarded as representative of how successful policy entrepreneurship can promote the transformation of governmental functions.

\section{Discussion}

According to this case analysis, the regular meetings of the small leading team have played a vital role in promoting policy implementation under the reform launched by J Gov't. The effects of this kind of management action, particularly in the Chinese context, have not been fully explained. The informal accountability resulting from the meetings has influenced local actors' behaviour through a combination of mechanisms that support the accomplishment of the policy reform's targets and objectives. In the following sections, we elaborate on this informal accountability and the corresponding effects on policy implementation, and draw on additional insights to further understand the informal accountability dynamics. 
As we observed, the bureaus involved in the small leading-team meetings were held accountable to the FDM, who was authorised to coordinate them regardless of the formal hierarchical structure that applied before the pilot reform. There was little formal agreement, however, on how each of the actors was to implement the policies or be held accountable. The objectives and the responsibilities of each actor were largely implicit and were subject to constant change and refinement, and the dialogue and agreement among the meeting members was mainly dependent on the moderator's improvisation and discretion. In addition, the rewards and sanctions for success or failure were ambiguous and neither ex ante or ex post formal monetary incentives or punishments have been applied so far. The interactions across meetings do not only rely on formalised rules, but also on being reproduced via informal guanxi such as patron-client relations and interpersonal relationships.

Informal accountability can be distinguished from formal accountability in several aspects such as facilitative behaviour, norms, and informal rewards and sanctions. First, the meetings exhibited explicit facilitative behaviour through relationship building, frequent and ongoing communication, information sharing, and recognising and acknowledging responsibility for mistakes. This gave public officials a nudge to achieve compliance by frequent scrutiny in the meetings. Second, norms refer to the shared values or the informal code of conduct among network actors, by which they can distinguish between appropriate and inappropriate behaviour in specific settings (Romzek et al. 2012), such as weekly meetings. An obvious norm derives from the fact that the local cadres involved in pilot reform were concerned about the legitimacy of their conduct. Finally, informal rewards and sanctions were key components of informal accountability in this study, along with the meetings. Instead of additional bonuses, career promotions or punishments, informal rewards and sanctions were revealed and concealed through the subtle and intricate gestures of meeting members.

As described, uncertainty and risk aversion made local officials reluctant to pursue policy implementation before the pilot reform. In essence, these officials exhibit two types of behavioural characteristics. First, they worried about the additional workload associated with the reform. In China's centralised institutional system, it is difficult to avoid this lack of sustainable incentives and to achieve the corresponding commitment. Through the series of meetings, however, these rational actors decided to collaborate and proceed with the policy implementation. As noted, 
evidence shows that informal accountability, incorporated in the small leading team meetings and supported by interpersonal ties, has contributed to the success of J Gov't pilot reform during the policy implementation process. This innovative approach ensured the success of their endeavour.

Compared with the subsequent comprehensive reform across mainland China that took place one year later, the pilot reform enacted by J Gov't displayed proactive and exploratory initiatives, which demonstrate the feasibility of and the possible barriers to conducting reform. This exploratory case study provides a unique insight into the institutional logic behind the actions of Chinese local government in response to the ongoing reform directed from the top down. Our analysis shows that informal accountability, consisting of informal facilitative behaviour, norms, and sanctions and rewards, can contribute significantly to reinforce motivation and build capacity in local actors. Regular cross-sectoral meetings play a key role through informal accountability and encourage local cadres to meet their reform responsibilities in the local political arena.

\section{Conclusion}

This study extends previous research on policy implementation by focusing on a distinct organisational phenomenon: the meetings of a small leading team to promote pilot reform. We derive preliminary findings from an exploratory case study in mainland China. First, this reveals that local government leadership can successfully utilise informal accountability generated by regular meetings authorised to promote the policy implementation. This type of meeting cultivates a networking and holistic approach among multiple bureaus, involving interaction and joint decision-making, where the broad reform goals have been specified and implemented by local government mandate.

The case of J Gov't's pilot reform provides a specific example of comprehensive administrative reform in mainland China today. As a pioneer of this round of reform, J Gov't provides a positive example for other local governments to implement reform. J Gov't was prudent and smart to comply with directions from superior agencies while making the policy implementation feasible in practice. The example offers two lessons when finding a solution to difficult-to-implement problems. First, it is essential to select leaders with qualities of perseverance and political wisdom, who can reinforce the motivations of subordinates and build 
up organisational capacity to complete tasks adroitly. Second, effective meetings provide a political arena for designing, implementing and evaluating several policy issues before scaling-up the local experiment. These lessons contribute to the understanding of how to promote ongoing comprehensive reform.

Inevitably, this study has significant limitations. While the case study approach is an effective strategy for developing a theory, this method does not allow the theory to be tested for more general application. This exploratory study, however, demonstrates a local government behavioural pattern when responding to the advocacy and requirements of the 3rd Plenary Session of the 18th CPC Central Committee. Alternative patterns for promoting policy implementation under the reform may be applicable, and thus further comparative and quantitative studies are required.

\section{References}

Behn, RD 2001, Rethinking Democratic Accountability, Brookings Institution Press, Washington, DC.

Bovens, M 2007, 'Analyzing and assessing public accountability: a conceptual framework', European Law Journal, vol 13, pp 447-68, doi.org/10.1111/ j.1468-0386.2007.00378.x.

Chan, HS \& Gao, J 2009, 'Putting the cart before the horse: accountability or performance?', The Australian Journal of Public Administration, vol 68, pp S51-S61, doi.org/10.1111/j.1467-8500.2009.00621.x.

Christensen, T \& Lægreid, P 2016, 'Accountability relations in unsettled situations: administrative reform and crises', working paper, Stein Rokkan Centre for Social Studies.

Eisenhardt, KM \& Graebner, ME 2007, 'Theory building from cases: opportunities and challenges', Academy of Management Journal, vol 50, pp 25-32, doi.org/ 10.5465/amj.2007.24160888.

Heilmann, S \& Melton, O 2013, 'The reinvention of development planning in China, 1993-2012', Modern China, vol 39, pp 580-628, doi.org/ $10.1177 / 0097700413497551$. 
Odermatt, I, König, CJ, Kleinmann, M, Nussbaumer, R, Rosenbaum, A, Olien, JL \& Rogelberg, SG 2017, 'On leading meetings: linking meeting outcomes to leadership styles', Journal of Leadership \& Organizational Studies, vol 24, pp 189-200, doi.org/10.1177/1548051816655992.

Podger, A \& Yan, B 2013, 'Public administration in China and Australia: different worlds but similar challenges', Australian Journal of Public Administration, vol 72, pp 201-19, doi.org/10.1111/1467-8500.12023.

Romzek, B, LeRoux, K \& Blackmar, JM 2012, 'A preliminary theory of informal accountability among network organizational actors', Public Administration Review, vol 72, pp 442-53, doi.org/10.1111/j.1540-6210.2011.02547.x.

Saz-Carranza, A, Salvador Iborra, S \& Albareda, A 2016, 'The power dynamics of mandated network administrative organizations', Public Administration Review, vol 76, pp 449-63, doi.org/10.1111/puar.12445.

Wu, X, Ramesh, M \& Yu, J 2017, 'Autonomy and performance: decentralization reforms in Zhejiang Province, China', Public Administration and Development, vol 37, no 2, pp 94-109, doi.org/10.1002/pad.1786.

Yang, K \& Dubnick, M 2016, 'Introduction: accountability study moving to the next level', Public Performance \& Management Review, vol 40, pp 201-07, doi.org/10.1080/15309576.2016.1266880.

Yasuda, JK Kojiro 2015, 'Why food safety fails in China: the politics of scale', The China Quarterly, vol 223, pp 745-69, doi.org/10.1017/S0305741015 00079X.

Yin, RK 2003, Case Study Research: Design and Methods, Sage, Los Angeles. 
This text is taken from Designing Governance Structures for Performance and Accountability: Developments in Australia and Greater China, edited by Andrew Podger, Tsai-tsu Su, John Wanna, Hon S. Chan and Meili Niu, published 2020 by ANU Press, The Australian National University, Canberra, Australia.

doi.org/10.22459/DGSPA.2020.10 